\title{
Retrosigmoid Versus Translabyrinthine Approach for Acoustic Neuroma Resection: An Assessment of Complications and Payments in a Longitudinal Administrative Database
}

Tyler Cole ${ }^{1}$, Anand Veeravagu ${ }^{2}$, Michael Zhang ${ }^{2}$, Tej Azad ${ }^{2}$, Christian Swinney ${ }^{2}$, Gordon H. Li ${ }^{2}$, John K. Ratliff ${ }^{2}$, Steven L. Giannotta ${ }^{3}$

1. Medical Student, Stanford University School of Medicine 2. Department of Neurosurgery, Stanford University School of Medicine 3. Department of Neurological Surgery, Keck School of Medicine of USC

$\square$ Corresponding author: Tej Azad,tdazad@gmail.com

Disclosures can be found in Additional Information at the end of the article

\section{Abstract}

Object

Retrosigmoid (RS) and translabyrinthine (TL) surgery remain essential treatment approaches for symptomatic or enlarging acoustic neuromas (ANs). We compared nationwide complication rates and payments, independent of tumor characteristics, for these two strategies.

\section{Methods}

We identified 346 and 130 patients who underwent RS and TL approaches, respectively, for AN resection in the 2010-2012 MarketScan database, which characterizes primarily privatelyinsured patients from multiple institutions nationwide.

Results

Although we found no difference in 30-day general neurological or neurosurgical complication rates, in TL procedures there was a decreased risk for postoperative cranial nerve (CN) VII injury (20.2\% vs $10.0 \%$, CI $0.23-0.82$ ), dysphagia (10.4\% vs $3.1 \%$, CI $0.10-0.78$ ), and dysrhythmia (8.4\% vs $2.3 \%$, CI 0.08-0.86). Overall, there was no difference in surgical repair rates of CSF leak; however, intraoperative fat grafting was significantly higher in TL approaches (19.8\% vs 60.2\%, CI 3.95-9.43). In patients receiving grafts, there was a trend towards a higher repair rate after RS approach, while in those without grafts, there was a trend towards a higher repair rate after TL approach. Median total payments were \$16,856 higher after RS approaches ( $\$ 67,774$ vs $\$ 50,918, \mathrm{p}<0.0001$ ), without differences in physician or 90 -day postoperative payments.

\section{Conclusions}

Using a nationwide longitudinal database, we observed that the TL, compared to RS, approach for AN resection experienced lower risks of CN VII injury, dysphagia, and dysrhythmia. There was no significant difference in CSF leak repair rates. The payments for RS procedures exceed provided the original author and source are credited.

\section{How to cite this article}

Cole T, Veeravagu A, Zhang M, et al. (October 30, 2015) Retrosigmoid Versus Translabyrinthine Approach for Acoustic Neuroma Resection: An Assessment of Complications and Payments in a Longitudinal Administrative Database. Cureus 7(10): e369. DOI 10.7759/cureus.369 
private sources will further clarify these trends.

Categories: Neurosurgery

Keywords: acoustic neuroma, csf leak, payments, retrosigmoid, translabyrinthine, fat grafting

\section{Introduction}

Surgical intervention remains a viable treatment option for symptomatic or progressively enlarging acoustic neuromas (AN) [1]. The most common surgical approaches to address these tumors are retrosigmoid (RS) and translabyrinthine (TL) [2-3]. A third, middle fossa approach can be considered; however, it has a more limited indication for small intracanalicular tumors [4]. The choice of either the RS or TL approach is dictated by the patient and tumor characteristics, and each approach demonstrates preferential utility in specific situations. While a number of predictive clinical factors have been studied, the relative outcomes of each approach continue to be debated [5-8]. These include tumor size, patient age and overall health status, the anatomy of the vestibule and cerebellopontine angle (CPA), involvement of the brainstem and facial nerve, and the degree of extension into the internal acoustic canal (IAC).

In general, the RS approach is considered more versatile, enabling removal of tumors largely independent of size. In contrast with a TL approach, an RS resection can offer hearing preservation [9]. The RS approach offers the surgeon an improved access to the root entry zone of the acoustic nerve. Disadvantages of the RS approach include the necessity for cerebellar retraction and more limited access to cranial nerve $(\mathrm{CN})$ VII and the cochlear nerves in the distal IAC, increasing the potential for subtotal resection. The TL approach is favored in patients with non-serviceable hearing and in patients with large tumors who have a low probability of hearing preservation [10]. Furthermore, the TL approach offers early identification of the CN VII in the auditory canal during surgery and eliminates any need for cerebellar retraction [11-12].

Although the advantages and disadvantages of different approaches for AN resection have been extensively reported on, a large-scale study to enable their accurate comparison is still greatly needed. The absence of a unified, consistent reporting of variables may contribute to variations in procedure outcomes. For example, in their meta-analysis, Ansari, et al. reported that the RS approach was the most versatile for facial nerve preservation, but it also led to a higher risk of postoperative pain and cerebrospinal fluid (CSF) fistula relative to the middle fossa or TL approach [13]. Meanwhile, Copeland, et al. reported in a recent single-institution, prospective analysis (1999-2012) that the TL approach instead resulted in an increased risk of developing a CSF leak postoperatively [14]. In this retrospective study, we sought to quantify and compare the complete postoperative complication profile of AN resection by retrosigmoid and translabyrinthine approaches with the aid of a nationwide administrative database.

\section{Materials And Methods}

\section{Study design and data source}

We performed a retrospective, longitudinal analysis of RS and TL approaches in procedures treating acoustic neuromas from a national database from years 2010-2012. Inpatient and outpatient data were obtained from the Thomson Reuters MarketScan Commercial Claims and Encounters and Medicare Supplemental and Coordination of Benefits databases, administered by Truven Health Analytics. The MarketScan dataset includes data from over 100 payers and includes inpatient, outpatient, and pharmacy services from a range of large employers, health plans, governmental organizations, and public organizations. 


\section{Cureus}

\section{Setting and participants}

We identified patients undergoing RS procedures with Common Procedural Terminology (CPT) code 61520 and TL procedures with CPT code 61526. A concurrent International Classification of Diseases (ICD-9) diagnosis code of 225.1 was required to indicate the presence of an acoustic neuroma. Comorbidities were assessed using the Deyo-Charlson and Elixhauser ICD-9 code groupings [15-16]. Supplementary Data 1 contains CPT and ICD-9 codes used in this study and not otherwise defined as part of established comorbidity measures. ICD-9 codes defining complications were only counted if not present within 180 days prior to the index procedure.

We identified surgeons using anonymized payer-specific physician identification numbers within inpatient records from the MarketScan data set. In some cases, a physician may have multiple identification numbers not reconciled among payers; however, due to the anonymization, we considered each physician number as unique. We then calculated the annual volume per individual surgeon identifier.

\section{Statistical analysis}

Tests of significance were performed using two-tailed tests. Categorical variables were analyzed using Fisher's Exact test; continuous variables were analyzed using Student's t-test. Due to the examination of a range of complications, significant results $(\mathrm{P}<0.05)$ were adjusted with the Holm-Bonferroni method to determine whether the hypothesis could be rejected. Data preparation and analysis were performed using SAS software (version 9.3; SAS Institute Inc., Cary, NC).

\section{Results}

\section{Demographics and comorbidities}

Within the MarketScan database during the studied period between 2010 and 2012, there were 346 and 130 patients who underwent an RS and TL approach for acoustic neuroma resection, respectively. There was no significant difference between the RS and TL groups for any of the patient factors, comorbidities, or hospitalization characteristics examined, shown in Table 1. This evaluation took into consideration patient age, patient gender, Medicare status, and the presence or absence of the following comorbidities: osteoporosis, tobacco use, congestive heart failure, hypertension, chronic obstructive pulmonary disease, myocardial infarction, diabetes, and obesity.

\begin{tabular}{|c|c|c|c|c|}
\hline & Retrosigmoid N = 346 & Translabyrinthine $\mathbf{N}=130$ & OR (CI) & P-value \\
\hline Age, mean (SD) & $48.8(12.3)$ & $49.3(11.9)$ & & 0.65 \\
\hline Follow-up, mean, (SD) & $315.3(218.6)$ & 352.7 (224.2) & & 0.096 \\
\hline Length of stay, mean (SD) & $5.4(5.2)$ & $5.1(5.7)$ & & 0.49 \\
\hline Discharge home, $\mathrm{N}(\%)$ & $304(86.1)$ & $121(91)$ & $1.63(0.84-3.16)$ & 0.17 \\
\hline \multicolumn{5}{|c|}{ Demographics and comorbidities, N (\%) } \\
\hline Male & $163(46.2)$ & $58(43.6)$ & $1.11(0.74-1.66)$ & 0.68 \\
\hline Medicare & $28(7.9)$ & $8(6)$ & $0.74(0.33-1.67)$ & 0.56 \\
\hline Tobacco use & $14(4)$ & $4(3.1)$ & $0.75(0.24-2.33)$ & 0.79 \\
\hline
\end{tabular}




\section{Cureus}

\begin{tabular}{|c|c|c|c|c|}
\hline Osteoporosis & $34(9.8)$ & $10(7.7)$ & $0.76(0.37-1.6)$ & 0.59 \\
\hline Hypertension & $118(34.1)$ & $43(33.1)$ & $0.96(0.62-1.46)$ & 0.91 \\
\hline CHF & $4(1.2)$ & $1(0.8)$ & $0.66(0.07-5.99)$ & 1.00 \\
\hline COPD & $29(8.4)$ & $8(6.2)$ & $0.72(0.32-1.61)$ & 0.56 \\
\hline MI & $5(1.4)$ & $2(1.5)$ & $1.07(0.2-5.56)$ & 1.00 \\
\hline Diabetes & $35(10.1)$ & $13(10)$ & $0.99(0.5-1.93)$ & 1.00 \\
\hline Obesity & $14(4)$ & $5(3.8)$ & $0.95(0.33-2.69)$ & 1.00 \\
\hline Region, N (\%) & & & & $<.0001$ \\
\hline Northeast & $115(32.6)$ & $21(15.8)$ & & \\
\hline North Central & $78(22.1)$ & $27(20.3)$ & & \\
\hline South & $103(29.2)$ & $74(55.6)$ & & \\
\hline West & $52(14.7)$ & $9(6.8)$ & & \\
\hline Unknown & $5(1.4)$ & $2(1.5)$ & & \\
\hline Insurance plan type, $\mathbf{N}(\%)$ & & & & 0.95 \\
\hline Comprehensive & $12(3.7)$ & $5(4)$ & & \\
\hline EPO & $6(1.8)$ & $1(0.8)$ & & \\
\hline HMO & $35(10.8)$ & $11(8.9)$ & & \\
\hline POS & $24(7.4)$ & $10(8.1)$ & & \\
\hline PPO & $224(68.9)$ & $90(72.6)$ & & \\
\hline POS with capitation & $1(0.3)$ & $0(0)$ & & \\
\hline CDHP & $13(4)$ & $3(2.4)$ & & \\
\hline HDHP & $10(3.1)$ & $4(3.2)$ & & \\
\hline
\end{tabular}

TABLE 1: Baseline cohort comparison of demographics, hospital-stay characteristics, and medical comorbidities between patients treated by retrosigmoid and translabyrinthine approaches.

EPO - exclusive provider organization; HMO - health maintenance organization; POS - point of service; PPO - preferred provider organization; CDHP - consumer-driven health plans; HDHP - hospital-driven health plan

\section{Comparative complication and revision procedure rates}

There was no significant difference in the incidence of overall general neurological or neurosurgical complications between the two procedures within the 30-day postoperative 


\section{Cureus}

period, as shown in Table 2. However, the TL procedure was associated with a decreased incidence of specific complications, including postoperative CN VII injury $(20.2 \%$ vs $10 \%, \mathrm{p}=$ $0.0096)$, dysphagia ( $10.4 \%$ vs $3.1 \%, p=0.0089)$, and dysrhythmia ( $8.4 \%$ vs $2.3 \%, p=0.022)$.

\begin{tabular}{|c|c|c|c|c|}
\hline & Retrosigmoid N (\%) & Translabyrinthine N (\%) & OR (Cl) & P-value \\
\hline Wound infection & $17(4.9)$ & $6(4.6)$ & $0.94(0.36-2.43)$ & 1.00 \\
\hline Wound dehiscence & $6(1.7)$ & $2(1.5)$ & $0.89(0.18-4.44)$ & 1.00 \\
\hline Wound hematoma & $11(3.2)$ & $5(3.8)$ & $1.22(0.42-3.58)$ & 0.78 \\
\hline Other wound complication & $9(2.6)$ & $2(1.5)$ & $0.59(0.12-2.74)$ & 0.74 \\
\hline Delirium & $2(0.6)$ & $2(1.5)$ & 2.69 (0.37-19.28) & 0.30 \\
\hline Pulmonary embolism & $6(1.7)$ & $0(0)$ & - & 0.20 \\
\hline Deep venous thrombosis & $8(2.3)$ & $5(3.8)$ & $1.69(0.54-5.26)$ & 0.36 \\
\hline Any thromboembolism & $4(1.2)$ & $1(0.8)$ & 0.66 (0.07-5.99) & 1.00 \\
\hline Pulmonary complication & $44(12.7)$ & $18(13.8)$ & $1.1(0.61-1.99)$ & 0.76 \\
\hline General neurological complication & $74(21.4)$ & 24 (18.5) & $0.83(0.5-1.39)$ & 0.53 \\
\hline Subarachnoid hemorrhage & $8(2.3)$ & $1(0.8)$ & 0.33 (0.04-2.64) & 0.46 \\
\hline Intracranial hemorrhage & $9(2.6)$ & $2(1.5)$ & $0.59(0.12-2.74)$ & 0.74 \\
\hline $\begin{array}{l}\text { Precerebral arterial } \\
\text { occlusion }\end{array}$ & $2(0.6)$ & $1(0.8)$ & $1.33(0.12-14.83)$ & 1.00 \\
\hline Cerebral artery occlusion & $10(2.9)$ & $3(2.3)$ & 0.79 (0.22-2.93) & 1.00 \\
\hline Transient ischemia attack & $3(0.9)$ & $0(0)$ & - & 0.57 \\
\hline Acute complication NOS & $5(1.4)$ & $1(0.8)$ & $0.53(0.06-4.57)$ & 1.00 \\
\hline Hemiplegia/hemiparalysis & $2(0.6)$ & $1(0.8)$ & $1.33(0.12-14.83)$ & 1.00 \\
\hline General neurosurgical complication & $50(14.5)$ & $16(12.3)$ & $0.83(0.45-1.52)$ & 0.66 \\
\hline latrogenic stroke & $6(1.7)$ & $4(3.1)$ & $1.8(0.5-6.48)$ & 0.47 \\
\hline Postop dysrhythmia & $29(8.4)$ & $3(2.3)$ & $0.26(0.08-0.86)$ & 0.022 \\
\hline Postop myocardial infarction & $9(2.6)$ & $4(3.1)$ & 1.19 (0.36-3.93) & 0.76 \\
\hline Postop dysphagia & 36 (10.4) & $4(3.1)$ & $0.27(0.1-0.78)$ & 0.0089 \\
\hline Postop CN VII injury & $70(20.2)$ & $13(10)$ & $0.44(0.23-0.82)$ & 0.0096 \\
\hline Any complication & 184 (53.2) & $58(44.6)$ & $0.71(0.47-1.06)$ & 0.10 \\
\hline 30-days all-cause readmission & 73 (21.1) & $21(16.2)$ & $0.72(0.42-1.23)$ & 0.25 \\
\hline
\end{tabular}

TABLE 2: Unadiusted complication rates amona patients treated bv retrosiamoid and 


\section{Cureus}

\section{translabyrinthine approaches}

CN - cranial nerve; NOS - not otherwise specified; (\%) percentage reflects proportions within respective RS and TL cohort

While there was no difference in the rate of lumbar drain placement $(11.2 \%$ vs $6.9 \%, \mathrm{p}=0.23)$ or surgical repair of CSF leak (11.2\% vs $11.5 \%, \mathrm{p}=0.87)$, the use of a fat graft during surgical repair of a CSF leak was significantly higher in the TL approach $(19.8 \%$ vs $60.2 \%, \mathrm{p}<0.0001)$, shown in Table 3. 


\section{Cureus}

\begin{tabular}{|c|c|c|c|c|}
\hline & $\begin{array}{l}\text { Retrosigmoid N } \\
\text { (\%) }\end{array}$ & $\begin{array}{l}\text { Translabyrinthine } \mathrm{N} \\
\text { (\%) }\end{array}$ & OR (Cl) & P-value \\
\hline Intraoperative tissue grafting & $70(19.8)$ & $80(60.2)$ & $\begin{array}{l}6.1(3.95- \\
9.43)\end{array}$ & $\begin{array}{l}< \\
0.0001\end{array}$ \\
\hline Lumbar drain placement & $39(11.2)$ & $9(6.9)$ & $\begin{array}{l}0.59(0.28- \\
1.26)\end{array}$ & 0.23 \\
\hline Within 30 days & $33(9.5)$ & $9(6.9)$ & $\begin{array}{l}0.71(0.33- \\
1.53)\end{array}$ & 0.47 \\
\hline With graft & $5(7.2)$ & $6(7.7)$ & $\begin{array}{l}1.07(0.31- \\
3.66)\end{array}$ & 1.00 \\
\hline Without graft & 34 (12.1) & $3(5.8)$ & $0.44(0.13-1.5)$ & 0.23 \\
\hline Repair of CSF leak & $39(11.2)$ & 15 (11.5) & $\begin{array}{l}1.04(0.55- \\
1.95)\end{array}$ & 0.87 \\
\hline Within 30 days & 31 (8.9) & $14(10.8)$ & $\begin{array}{l}1.24(0.64- \\
2.41)\end{array}$ & 0.60 \\
\hline With fat graft & $11(15.9)$ & $5(6.4)$ & $0.36(0.12-1.1)$ & 0.11 \\
\hline Without fat graft & $28(10)$ & $10(19.2)$ & $\begin{array}{l}2.14(0.97- \\
4.73)\end{array}$ & 0.093 \\
\hline $\begin{array}{l}\text { Surgeons performing } \geq 2 \text { AN procedures } \\
\text { annually }{ }^{\star}\end{array}$ & 25 (7.2) & $13(10)$ & $\begin{array}{l}1.44(0.71- \\
2.91)\end{array}$ & 0.34 \\
\hline Postoperative SRS & $16(4.7)$ & $7(5.5)$ & $\begin{array}{l}1.17(0.47- \\
2.92)\end{array}$ & 0.81 \\
\hline
\end{tabular}

TABLE 3: 30-day readmission rate and adjunctive procedures, including tissue grafting, drain placement, and CSF leak repair and SRS between retrosigmoid and translabyrinthine approaches

CSF - cerebral spinal fluid; AN - acoustic neuroma; SRS - stereotactic radiosurgery ( ${ }^{*}$ Limited to procedures recorded within the MarketScan database, not indicative of absolute AN surgeon volume)

In patients with grafts, the need for a CSF leak repair trended towards being higher in the RS group (15.9\% vs $6.4 \%, \mathrm{p}=0.11$ ). However, in those without fat grafts, it was higher in the TL group (10\% vs $19.2 \%, \mathrm{p}=0.093)$. Of note, we also found that patients who underwent the TL approach and received fat grafting were less likely to develop CSF leak requiring surgical intervention $(6.4 \%$ vs $19.2 \%, \mathrm{p}=.047)$. In contrast, there was a trend towards increased risk of CSF leak requiring surgical intervention with fat grafting in patients who received an RS approach $(15.9 \%$ vs $10 \%, \mathrm{p}=0.20)$.

Procedure payments, length of stay and readmission rates 


\section{Cureus}

The RS approach resulted in higher median total payments $(\$ 67,774$ vs $\$ 50,918, \mathrm{p}=0.0004)$ and hospital payments $(\$ 50,351$ vs $\$ 36,855, \mathrm{p}=0.0025)$. There was no significant difference between the two procedures for median physician payments $(\$ 8,575$ vs $\$ 7,499, p=0.17)$ or aggregate 90 -day postoperative payments $(\$ 18,607$ vs $\$ 12,513, \mathrm{p}=0.15)$. There was no difference in the length of hospital stay, follow-up, or discharge home. These findings are shown in Table 4.

\begin{tabular}{|c|c|c|c|}
\hline & Retrosigmoid N = 346 & Translabyrinthine $\mathbf{N}=130$ & P-value \\
\hline Hospital payments, median (IQR) & 50351 (46702) & 36855 (34438) & 0.0025 \\
\hline Physician payments, median (IQR) & $8575(8326)$ & $7499(5670)$ & 0.17 \\
\hline Total payments, median (IQR) & $67774(503 / 4)$ & $50918(355 / 2)$ & 0.0004 \\
\hline 90-day post-discharge payments, median (IQR) & 18607 (39829) & 12513 (39939) & 0.15 \\
\hline
\end{tabular}

TABLE 4: Comparative median immediate and 90-day post-discharge payments between retrosigmoid and translabyrinthine approaches

IQR - interquartile range

\section{Surgical volume and adverse events}

Surgeons who are recorded in the MarketScan database as performing at least two AN procedures annually had a decreased incidence of CN VII injury $(18.7 \%$ vs $2.6 \%, \mathrm{p}=.0072)$ and postoperative dysphagia ( $8.9 \%$ vs $2.6 \%, p=.24)$, as well as a trend towards decreased need for repair of CSF leak ( $12 \%$ vs $2.6 \%, p=0.11$ ), compared to surgeons performing fewer than two procedures per year. These results are shown in Table 5. Though not statistically significant, we also noted a strong trend for surgeons who performed more than two procedures per year to utilize intraoperative fat grafting $(44.7 \%$ vs $29.5 \%, \mathrm{p}=.066)$. The annual volume of procedures that a given surgeon performed did not impact the incidence of postoperative dysrhythmia. 


\section{Cureus}

\begin{tabular}{|c|c|c|c|c|}
\hline & $\begin{array}{l}\text { Surgeons Performing < } 2 \\
\text { Procedures Annually* }\end{array}$ & $\begin{array}{l}\text { Surgeons Performing } \geq 2 \\
\text { Procedures Annually* }\end{array}$ & $\begin{array}{l}\text { OR }(95 \% \\
\text { Cl) }\end{array}$ & $\begin{array}{l}\mathrm{P}- \\
\text { value }\end{array}$ \\
\hline $\mathrm{N}$ treated patients & 438 & 38 & & \\
\hline Postop CN VII injury & $82(18.7)$ & $1(2.6)$ & $\begin{array}{l}0.12(0.02- \\
0.87)\end{array}$ & 0.0072 \\
\hline Postop dysphagia & $39(8.9)$ & $1(2.6)$ & $\begin{array}{l}0.28(0.04- \\
2.07)\end{array}$ & 0.24 \\
\hline Postop dysrhythmia & $30(6.8)$ & $2(5.3)$ & $\begin{array}{l}0.76(0.17- \\
3.29)\end{array}$ & 1.00 \\
\hline $\begin{array}{l}\text { Intraoperative tissue } \\
\text { grafting }\end{array}$ & $130(29.5)$ & $17(44.7)$ & $\begin{array}{l}1.94(0.99- \\
3.79)\end{array}$ & 0.066 \\
\hline Repair of CSF leak & $53(12)$ & $1(2.6)$ & $\begin{array}{l}0.2(0.03- \\
1.47)\end{array}$ & 0.11 \\
\hline
\end{tabular}

TABLE 5: Pertinent complication rates and adjunctive procedures, stratified by annual surgeon experience with any acoustic neuroma resection approach

$\mathrm{CN}$ - cranial nerve; CSF - cerebral spinal fluid. ( ${ }^{*}$ Limited to procedures recorded within the MarketScan database, not indicative of absolute AN surgeon volume)

\section{Discussion}

This national sample of patients undergoing surgical intervention for acoustic neuromas between 2010 and 2012 compared the complications and costs between these two common approaches. We observed that an RS approach, relative to a TL one, was associated with an increased rate of postoperative facial nerve injury (18.7\% vs 2.6\%) and postoperative dysphagia (8.9\% vs 2.6\%). Although the frequency of CSF leak was equivalent between approaches, the choice of intraoperative fat grafting reflected each procedure's respective needs for adequate dural repair [17]. Total hospital payments for a TL approach were significantly lower than that required for an RS approach $(\$ 36,855$ vs $\$ 50,351$ ) and did not markedly impact payments associated with postoperative care.

Follow-up analyses did not indicate that variations in the length of stay or lumbar drain placement contributed to the difference in costs between RS and TL approaches. However, the diverging postoperative complication rates, particularly in relationship to provider volume, may play a role. Prior work has reported that high volume centers achieve a lower average cost of hospitalization [18-19]. Low volume surgeons, using the more versatile retrosigmoid, may encounter a higher complication rate, potentially leading to the increased use of hospital resources not available in the MarketScan database [20]. Viewed collectively, our findings can inform practitioners by determining the composite risks of AN surgery in the broader neurosurgical community, as opposed to evaluating results from just one or a few centers. Otherwise, the general neurological complication rates between each surgical approach were comparable. 
The rate of facial nerve dysfunction associated with AN surgery is an important clinical outcome. Affecting one out of five RS patients in our analysis, it was the most prominent individual complication in the early postoperative phase. The TL approach is traditionally thought to provide a more anatomically accommodating view of the facial nerve and, therefore, can limit facial nerve injury [21]. Existing studies have reported comparable facial nerve dysfunction rates [22-24]. In a series of 200 operations utilizing the RS approach, Samii, et al. reported a 19\% rate of facial nerve dysfunction (House-Brackmann Grade IV and V) with a mean follow-up of 24 months [25].

Meanwhile, other studies emphasizing additional parameters or with longer follow-up have reported varying complication rates. For example, Ansari, et al. reported that at 23.3 months median follow-up, there was no difference between surgical approaches when treating smaller tumors and that an RS approach can actually have better facial nerve preservation rates when treating larger tumors [13]. Since facial nerve dysfunction is known to potentially recover within the first postoperative year, complication rates between RS and TL may become statistically masked over time [26-29]. By limiting our study to the early postoperative phase, we avoid any confounding temporal variations in reporting.

Although less common than facial nerve dysfunction, postoperative injury to the neighboring vagus nerve, presenting as dysphagia, is another important clinical outcome for patients and providers. The complication is again largely limited to the early postoperative phase, with follow-up surveys indicating that $71 \%$ recover from their vagal palsies. Those with palsies were no more likely than those who never presented with palsies to have long-term difficulties related to their voice or swallowing [30]. Nevertheless, patients continue to express concern over facial and vagal nerve injuries and continue to perceive cranial nerve preservation as an indicator of surgical success $[21,31]$. Fortunately, these often transient postoperative symptoms do not ultimately impact patients' quality of life outcomes [32]. Perhaps, also related to the involvement of the vagus nerve, we identified a higher rate of dysrhythmia in RS procedures; however, this did not affect the rate of postoperative transient ischemic attacks, arterial occlusion, or myocardial infarction.

Interestingly, the rate of CSF leak is comparable between surgical approaches. Although there remains no consensus on the best graft protocol for preventing postoperative CSF leaks, there is encouraging data showing that fat grafting can reduce the rate of a dural leak to $0-7.4 \%$ [3337]. Within our data, the choice to include a graft did vary based on the surgical approach. There was an increased trend of incorporating intraoperative fat grafts for TL approaches, though this was markedly lower (60.2\%) than we expected, given the relative consensus within the neurosurgical literature around fat grafting with employment of the TL approach [20]. The lower than expected rate of fat grafting in TL procedures may be a result of varying institutional coding practices. Nevertheless, the importance of grafting in TL approach was reaffirmed when we found that use of a graft was protective against the risk of a dural leak requiring surgical intervention in TL approaches. Given this finding and the existing neurosurgical literature, we encourage this additional closure technique when possible.

Finally, we observed significant variation in inpatient financial impact with AN resections. The difference in median total payment exceeded $\$ 15,000$ between the two approaches, and this margin is likely to play an increasingly larger role in clinical decision-making as the cost of AN surgery continues to rise [38-39]. Since recurrence is already very low, future changes in the financial and clinical cost of surgery will likely heavily reflect the increasing costs of the primary surgery [38]. These costs of RS surgery also can be weighed alongside the wellcharacterized risks of hearing loss, a known absolute complication, in TL surgery. Ansari, et al. indicated that the probability of hearing loss is about $64.3 \%$ in tumors $<1.5 \mathrm{~cm}$ and $71.6 \%$ in those between 1.5 and $3.0 \mathrm{~cm}$ when resected by the RS approach [13]. Thus, when microsurgery is indicated and tumor features cannot guide the surgical approach, early postoperative risk of 
facial nerve dysfunction, vagal nerve dysfunction, and increased hospital payments of RS approach should collectively be considered.

Our study has several limitations, which should be noted. The MarketScan dataset does not characterize tumor size or location (e.g.. intracanalicular involvement), which frequently guides the surgical approach. Our analysis is intended as a broad overview of the comparative outcomes of the procedures independent of preoperative evaluation and planning. Secondly, the MarketScan database is limited in assessing surgical volume or providers, as it only captures procedures whose payment is provided by insurers within the database. Our assessment of volume is, therefore, more reflective of relative, and not absolute, volume differences. We are also not able to differentiate between academic and private practices, which frequently vary in case distribution and complexity. Outcome differences may be attributable to surgeons' experience with acoustic neuroma management and the approaches for resection. In our analysis of CSF leaks, it is important to note we consistently discussed the rates of CSF leak requiring surgical intervention. We are unable to report the objective rates, as the ICD-9 codes that may provide that information is unreliable. Furthermore, because cranial nerve palsies have been shown to resolve and hospital costs are most prominent during the initial hospitalizations, we believe our data appropriately focuses on the symptomatically and resource-intensive period relevant for accurate quality assessment.

Our report, which is accompanied by the limitations of all retrospective studies, provides an updated, large-scale survey of current AN surgical care. These results can serve to inform future evaluations of both community- and academic-based practices.

\section{Conclusions}

From a nationwide, administrative database spanning 2010-2012, AN resection by TL approach was found to have a lower rate of CN VII injury, dysphagia, and dysrhythmia compared to that by RS approach. Although there was no significant difference in CSF leak repair rates, the rate for tissue grafting differed by approach. Surgeons performing multiple AN resections had lower rates of CN VII dysfunction and lower CSF leak repair rates, independent of the procedure. The mean payment for RS procedures was significantly greater than that for TL procedures; however, there was no difference in post-hospitalization costs.

\section{Appendices}

Supplementary Data 1. CPT and ICD-9-CM coding utilized for cohort selection, comorbidity assessment (not elsewhere defined as part of established comorbidity measures), and postoperative outcome analysis; MI, myocardial infarction; CN, cranial nerve; CSF, cerebrospinal fluid

Comorbidity or Postoperative Outcome Coding

Tobacco use (ICD-9) - 305.1, V15.82, 989.84, 649.0

Osteoporosis (ICD-9) - 733, V17.81, 731.3, V82.81

General neurological complication (ICD-9) - 430, 431, 432, 433, 434, 435, 436, 438.2, 438.3, $438.4,438.5$

General neurosurgical complication (ICD-9) - 997

Dysrhythmia (ICD-9) - 427, 426.1, 426, 426.3, 426.4, 426.5, 426.6, 426.7, 426.8 
MI (ICD-9) - 410, 412, 998.0, 997.1, 411, 429.7

Dysphagia (ICD-9) - 787.2

CN VII injury (ICD-9) - 351

Lumbar drain placement (CPT) - 62272

Tissue grafting (CPT) - 20926

Repair of CSF leak (CPT) - 61618, 61619, 62100, 69670

Stereotactic radiosurgery (CPT) - 61796, 61797, 61798, 61799, 61800, 63620, 63621

\section{Additional Information}

\section{Disclosures}

Human subjects: Consent was obtained by all participants in this study. This is a retrospective study and does not require consent as it was obtained at the time of treatment. Animal subjects: All authors have confirmed that this study did not involve animal subjects or tissue. Conflicts of interest: In compliance with the ICMJE uniform disclosure form, all authors declare the following: Payment/services info: All authors have declared that no financial support was received from any organization for the submitted work. Financial relationships: All authors have declared that they have no financial relationships at present or within the previous three years with any organizations that might have an interest in the submitted work. Other relationships: This article was supported by a research grant from the Orthopedic Research and Education Foundation, the Walsh Foundation, and the Stanford University Medical Scholars Program. The authors have no ethical issues or conflicts of interest to report.

\section{References}

1. Arthurs BJ, Fairbanks RK, Demakas JJ, Lamoreaux WT, Giddings NA, Mackay AR, Cooke BS, Elaimy AL, Lee CM: A review of treatment modalities for vestibular schwannoma . Neurosurg Rev. 2011, 34:265-77. 10.1007/s10143-011-0307-8

2. Elhammady MS, Telischi FF, Morcos JJ: Retrosigmoid approach: indications, techniques, and results. Otolaryngol Clin North Am. 2012, 45:375-97. 10.1016/j.otc.2012.02.001

3. Arriaga MA, Lin J: Translabyrinthine approach: indications, techniques, and results . Otolaryngol Clin North Am. 2012, 45:399-415. 10.1016/j.otc.2011.12.009

4. Angeli S: Middle fossa approach: indications, technique, and results . Otolaryngol Clin North Am. 2012, 45:417-38. 10.1016/j.otc.2011.12.010

5. Samii M, Matthies C: Management of 1000 vestibular schwannomas (acoustic neuromas): hearing function in 1000 tumor resections. Neurosurgery. 1997, 40:248-60. 10.1097/00006123-199702000-00005

6. Foote KD, Friedman WA, Buatti JM, Meeks SL, Bova FJ, Kubilis PS: Analysis of risk factors associated with radiosurgery for vestibular schwannoma. J Neurosurg. 2001, 95:440-49. 10.3171/jns.2001.95.3.0440

7. Ito E, Saito K, Yatsuya H, Nagatani T, Otsuka G: Factors predicting growth of vestibular schwannoma in neurofibromatosis type 2. Neurosurg Rev. 2009, 32:425-33. 10.1007/s10143009-0223-3

8. Phillips DJ, Kobylarz EJ, De Peralta ET, Stieg PE, Selesnick SH: Predictive factors of hearing preservation after surgical resection of small vestibular schwannomas. Otol Neurotol. 2010, 31:1463-68. 10.1097/MAO.0b013e3181f6c8d2

9. Gharabaghi A, Samii A, Koerbel A, Rosahl SK, Tatagiba M, Samii M: Preservation of function in vestibular schwannoma surgery. Neurosurgery. 2007, 60:124-28. 
10. Day JD, Chen DA, Arriaga M: Translabyrinthine approach for acoustic neuroma. Neurosurgery. 2004, 54:391-95. 10.1227/01.NEU.0000103668.26590.5A

11. Chamoun R, MacDonald J, Shelton C, Couldwell WT: Surgical approaches for resection of vestibular schwannomas: translabyrinthine, retrosigmoid, and middle fossa approaches. Neurosurg Focus. 2012, 33:e9. 10.3171/2012.6.focus12190

12. Sluyter S, Graamans K, Tulleken CA, Van Veelen CW: Analysis of the results obtained in 120 patients with large acoustic neuromas surgically treated via the translabyrinthinetranstentorial approach. J Neurosurg. 2001, 94:61-66. 10.3171/jns.2001.94.1.0061

13. Ansari SF, Terry C, Cohen-Gadol AA: Surgery for vestibular schwannomas: a systematic review of complications by approach. Neurosurg Focus. 2012, 33:e14.

10.3171/2012.6.focus12163

14. Copeland WR, Mallory GW, Neff BA, Driscoll CL, Link MJ: Are there modifiable risk factors to prevent a cerebrospinal fluid leak following vestibular schwannoma surgery?. J Neurosurg. 2015, 122:312-16. 10.3171/2014.10.jns14432

15. Elixhauser A, Steiner C, Harris DR, Coffey RM: Comorbidity measures for use with administrative data. Med Care. 1998, 36:8-27. 10.1097/00005650-199801000-00004

16. Deyo RA, Cherkin DC, Ciol MA: Adapting a clinical comorbidity index for use with ICD-9-CM administrative databases. J Clin Epidemiol. 1992, 45:613-19. 10.1016/0895-4356(92)90133-8

17. Ahmed OH, Mahboubi H, Lahham S, Pham C, Djalilian HR: Trends in demographics, charges, and outcomes of patients undergoing excision of sporadic vestibular schwannoma.. Otolaryngol Head Neck Surg. 2014, 150:266-74. 10.1177/0194599813507234

18. Slattery WH, Schwartz MS, Fisher LM, Oppenheimer M: Acoustic neuroma surgical cost and outcome by hospital volume in California. Otolaryngol Head Neck Surg. 2004, 130:726-35. 10.1016/j.otohns.2004.02.008

19. Welling DB, Slater PW, Thomas RD, McGregor JM, Goodman JE: The learning curve in vestibular schwannoma surgery. Am J Otol. 1999, 20:644-48.

20. Meyer SA, Post KD: Acoustic Neuroma. Youmans Neurological Surgery, 6th edition. Winn RH (ed): Saunders, Philadelphia, Pennsylvania; 2011. 1:1460-75.

21. Eldridge R, Parry D: Vestibular schwannoma (acoustic neuroma). Consensus development conference. Neurosurgery. 1992, 30:962-64. 10.1227/00006123-199206000-00030

22. Jung S, Kang SS, Kim TS, Kim HJ, Jeong SK, Kim SC, Lee JK, Kim JH, Kim SH, Lee JH: Current surgical results of retrosigmoid approach in extralarge vestibular schwannomas. Surg Neurol. 2000, 53:370-77. 10.1016/S0090-3019(00)00196-8

23. Gormley WB, Sekhar LN, Wright DC, Kamerer D, Schessel D: Acoustic neuromas: results of current surgical management. Neurosurgery. 1997, 41:50-58. 10.1097/00006123-19970700000012

24. Nonaka Y, Fukushima T, Watanabe K, Friedman AH, Sampson JH, Mcelveen JT Jr, Cunningham CD 3rd, Zomorodi AR: Contemporary surgical management of vestibular schwannomas: analysis of complications and lessons learned over the past decade. Neurosurgery. 2013, 72:ons103-15. 10.1227/NEU.0b013e3182752b05

25. Samii M, Gerganov V, Samii A: Improved preservation of hearing and facial nerve function in vestibular schwannoma surgery via the retrosigmoid approach in a series of 200 patients. J Neurosurg. 2006, 105:527-35. 10.3171/jns.2006.105.4.527

26. Ho SY, Hudgens S, Wiet RJ: Comparison of postoperative facial nerve outcomes between translabyrinthine and retrosigmoid approaches in matched-pair patients. Laryngoscope. 2003, 113:2014-20. 10.1097/00005537-200311000-00030

27. Soon SS, Goh SY, Bee YM, Poon JL, Li SC, Thumboo J, Wee HL: Audit of Diabetes-Dependent Quality of Life (ADDQoL) [Chinese Version for Singapore] questionnaire: reliability and validity among Singaporeans with type 2 diabetes mellitus. Appl Health Econ Health Policy. 2010, 8:239-49. 10.2165/11313920-000000000-00000

28. Sampath P, Holliday MJ, Brem H, Niparko JK, Long DM: Facial nerve injury in acoustic neuroma (vestibular schwannoma) surgery: etiology and prevention. J Neurosurg. 1997, 87:60-66. 10.3171/jns.1997.87.1.0060

29. Rivas A, Boahene KD, Bravo HC, Tan M, Tamargo RJ, Francis HW: A model for early prediction of facial nerve recovery after vestibular schwannoma surgery. Otol Neurotol. 2011, 32:826-33. 10.1097/MAO.0b013e31821b0afd

30. Starmer HM, Ward BK, Best SR, Gourin CG, Akst LM, Hillel A, Brem H, Francis HW: Patient- 
perceived long-term communication and swallow function following cerebellopontine angle surgery. Laryngoscope. 2014, 124:476-80. 10.1002/lary.24252

31. Nguyen NP, Frank C, Moltz CC, Vos P, Smith HJ, Karlsson U, Dutta S, Midyett A, Barloon J, Sallah S: Impact of dysphagia on quality of life after treatment of head-and-neck cancer . Int J Radiat Oncol Biol Phys. 2005, 61:772-78. 10.1016/j.ijrobp.2004.06.017

32. Cheng S, Naidoo Y, da Cruz M, Dexter M: Quality of life in postoperative vestibular schwannoma patients. Laryngoscope. 2009, 119:2252-57. 10.1002/lary.20217

33. Selesnick SH, Liu JC, Jen A, Newman J: The incidence of cerebrospinal fluid leak after vestibular schwannoma surgery. Otol Neurotol. 2004, 25:387-93. 10.1097/00129492200405000-00030

34. Netto AA, Colafemina JF, Centeno RS: Dural defect repair in translabyrinthine acoustic neuroma surgery and its implications in cerebrospinal fluid leak occurrence. J Neurol Surg B Skull Base. 2012, 73:327-30. 10.1055/s-0032-1321511

35. Goddard JC, Oliver ER, Lambert PR: Prevention of cerebrospinal fluid leak after translabyrinthine resection of vestibular schwannoma. Otol Neurotol. 2010, 31:473-77. 10.1097/MAO.0b013e3181cdd8fc

36. Wu H, Kalamarides M, Garem HE, Rey A, Sterkers O: Comparison of different wound closure techniques in translabyrinthine acoustic neuroma surgery. Skull Base Surg. 1999, 9:239-42. 10.1055/s-2008-1058132

37. Falcioni M, Mulder JJ, Taibah A, De Donato G, Sanna M: No cerebrospinal fluid leaks in translabyrinthine vestibular schwannoma removal: reappraisal of 200 consecutive patients. Am J Otol. 1999, 20:660-66.

38. Ahmed OH, Mahboubi H, Lahham S, Pham C, Djalilian HR: Trends in demographics, charges, and outcomes of patients undergoing excision of sporadic vestibular schwannoma. Otolaryngol Head Neck Surg. 2014, 150:266-74. 10.1177/0194599813507234

39. Sonig A, Khan IS, Wadhwa R, Thakur JD, Nanda A: The impact of comorbidities, regional trends, and hospital factors on discharge dispositions and hospital costs after acoustic neuroma microsurgery: a United States nationwide inpatient data sample study (2005-2009). Neurosurg Focus. 2012, 33:e3. 10.3171/2012.7.focus12193 